\title{
Characteristics and quality of clinical practice guidelines for depression in adults: a scoping review
}

\author{
Jessica Hanae Zafra-Tanaka', Sergio Goicochea-Lugo², David Villarreal-Zegarra ${ }^{1,3}$ and Alvaro Taype-Rondan ${ }^{4^{*}}$ (D)
}

\begin{abstract}
Background: Clinical Practice Guidelines (CPGs) should follow an adequate methodology using an evidence-based approach in order to provide reliable recommendations. However, little is known regarding the quality of CPGs for Depression, which precludes its adequate use by stakeholders and mental health professionals. Thus, the aim of this study was to conduct a scoping review to describe the characteristics and quality of CPGs for Depression in adults.

Methods: We searched CPGs for Depression in adults in eighteen databases. We included those that were published in English or Spanish between January 2014 and May 2018 and were based on systematic reviews of the evidence. Two independent authors extracted the characteristics, type and number of recommendations, and quality (using the Appraisal of Guidelines for Research and Evaluation-II [AGREE-II]) of each included CPG.

Results: We included eleven CPGs, of which 9/11 did not include the participation of patients in the development of the CPG, 4/11 CPGs had a score $\geq 70 \%$ in the overall evaluation of AGREE-II, and 3/11 CPGs had a score $\geq 70 \%$ in its third domain (rigor of development). In addition, only 5/11 CPGs shared their search strategy, while only 4/11 listed the selected studies they used to reach recommendations, and 7/11 CPGs did not clearly state which methodology they used to translate evidence into a recommendation.

Conclusions: Most of evaluated CPGs did not take into account the patient's viewpoints, achieved a low score in the rigor of development domain, and did not clearly state the process used to reach the recommendations. Stakeholders, CPCGs developers, and CPGs users should take this into account when choosing CPGs, and interpreting and putting into practice their issued recommendations.
\end{abstract}

Keywords: Major depression, Clinical practice guidelines, Quality, AGREE-II

\section{Background}

Depression is recognized as an important public health issue. By the year 2015 it affected around $4.4 \%$ of the population [1], and by the year 2016 it was responsible for approximately $6.75 \%$ of years lived with disability in adults worldwide [2]. Different actions are needed to improve the care of people suffering from depression, such as the development and implementation of adequate clinical practice guidelines (CPGs).

CPGs are classically defined as a set of "systematically developed statements to assist practitioner and patient

\footnotetext{
* Correspondence: alvaro.taype.r@gmail.com

${ }^{4}$ Universidad San Ignacio de Loyola, Unidad de Investigación para la Generación y Síntesis de Evidencias en Salud, Av. La Fontana 550, La Molina, Lima, Peru

Full list of author information is available at the end of the article
}

decisions about appropriate health care for specific clinical circumstances" [3]. CPGs can help to close gaps between evidence and policy, issuing recommendations in favor of the use of effective interventions and against the use of futile interventions [4]; CPGs are needed to establish reliable recommendations achieved through a clear methodology [5]. However, the methodology used for CPGs development is usually poorly defined and varies widely in content and quality between and within developing institutions [6], which may lead to inconsistency between recommendations. Accordingly, a study that compared recommendations from 23 CPGs published between 2007 and 2017 found high inconsistency in recommendations for second and third-line of pharmacological treatment of depression [7]. 
It is of great importance that stakeholders and mental health professionals are aware of the characteristics and quality of currently used CPGs for depression. The quality of the CPGs should be taken into account when interpreting and putting in practice recommendations issued in these CPGs. However, to our knowledge, only one study has assessed the quality of CPGs for depression and anxiety in children and youth [8], and we have not found studies that have described the quality of CPGs for depression in adults. Thus, the aim of this study was to describe the characteristics and quality of CPGs for depression in adults.

\section{Methods}

We performed a scoping review of CPGs for depression in adults published in the last 5 years and evaluated characteristics regarding scope, methods used to reach recommendations, and grading the strength of recommendations. We also assessed the quality of each CPG. The PRISMA guidelines for scoping reviews (PRISMA-ScR) were used to secure adequate reporting and to guarantee the replicability of the study [9].

A scoping review is "a form of knowledge synthesis, which incorporate a range of study designs to comprehensively summarize and synthesize evidence with the aim of informing practice, programs, and policy and providing direction to future research priorities" [10]. It is similar to a systematic review, but it mainly differs on the objective they pursue. While a systematic review aims to find an answer to a well-defined question, a scoping review can be used identify, map and discuss certain characteristics in papers or studies [11]. Given that our aim was to identify CPG and their characteristics, we decided to use the later.

\section{Eligibility criteria}

We included all CPGs, defined as a document that aimed to state recommendations, that fulfilled the following criteria: assessed screening, diagnosis or management of depression in adults; were published or totally/partially updated in the last 5 years (January 2014May 2018); full-text were available in English or Spanish; and used systematic reviews of the evidence to guide their recommendations. We decided to include only CPGs based on systematic reviews, based on the current CPG definition which states that they should be designed based on a systematic review of the evidence [12].

We excluded those CPGs that assessed specific types of depression such as bipolar or psychotic depression, or specific types of populations such as depression in patients with cancer or in older people after a stroke.

\section{Search strategy}

We performed a comprehensive search in eighteen databases. Our search strategy included terms related to depression and guidelines/practice guidelines. Searchers were performed by two independent researchers (JHZT and DVZ), and the last update was run in June 2018 (see Additional file 1).

\section{Study selection}

Two independent researchers (JHZT and DVZ) evaluated if the CPGs met the eligibility criteria for inclusion. When there were discrepancies, a consensus was reached after debating them among all the authors.

\section{Data extraction}

The following characteristics were extracted from the CPGs: authors; year of publication; country; involvement of patients or their representatives in the CPG development process; methodology used to reach recommendations; methodology used for grading the strength of recommendations; usage of minimally important difference (MID) when evaluating the effect of interventions; and the number of recommendations and good clinical practice (GCP).

We defined a recommendation as "all the statements in favor or against an intervention based on systematic reviews of the evidence, which typically include a formal assessment of the benefits and drawbacks of available treatment options" [13]. All the statements that synthetize opinions from an organized group of experts (expert consensus) and aim to describe "customary and expected care to be offered to patients" in situations where little to no evidence is available were considered as GCP [13].

We defined MID as a measure of the "smallest change in patient-reported outcomes of interest that patients perceive as important" [14].

\section{Quality appraisal}

To assess the quality of CPGs we used the Appraisal of Guidelines Research and Evaluation II (AGREE-II), which has 23 items distributed in six domains (scope and purpose, stakeholder involvement, rigor of development, clarity and presentation, applicability, and editorial independence). Each guideline was rated by two researchers. When a difference in two or more points in each item was found, the item was discussed to get to a consensus. Otherwise, we used the mean of the two raters for each item. Lastly, we followed the AGREE-II Instrument guideline to calculate the scores for each domain [15].

We considered that when a CPG had a total score $\geq$ $70 \%$ it had adequate quality, we also used the same cutoff for each of the domains of the AGREE-II Instrument. This cutoff point was taken from a previous study that evaluated the quality of depression CPGs in children [8]. Likewise, we considered that when a CPG had a score $\geq 70 \%$ in the third domain (rigor of development) 
of the AGREE-II Instrument, the CPG had an adequate rigor of development.

\section{Results}

We found twenty CPG for depression in adults published or updated between 2014 and 2018, of which thirteen performed systematic reviews to formulate their recommendations. Two CPGs were excluded from our study given that they were not available in full-text [16, 17], (See Additional file 2). Thus, we finally included eleven guidelines [18-28].

From the included guidelines, $2 / 11$ included patients in the process of development of the CPG (one as part of the guideline development group [NICE], and 1/11 during the external validation [GuiaSalud]). Regarding how the development group reached the recommendations, 3/11 did not clearly state how recommendations were reached (Korea, RANZCP, USTF), 4/11 used expert consensus but did not specify the criteria evaluated (ACP, APA, VADoD, BAP), and 4/11 used a well-specified methodology (either: Grades of Recommendation, Assessment, Development, and Evaluation [GRADE], Scottish Intercollegiate Guidelines Network [SIGN], or Canadian Network for Mood and Anxiety Treatments [CANMAT]). All included guidelines specified the system they used for grading the strength of recommendations (Table 1).

The number of recommendations stated by each CPG varied between one and 199 recommendations. Three CPGs focused on one topic: the Acupuncture CPG [19] that aimed to give recommendations regarding acupuncture treatment, the ACP guideline [22] that aimed to determine the usage of pharmacological versus nonpharmacological treatment, and the US-Taskforce guideline [25] that aimed to state how the screening of depression should be performed. The other eight CPGs addressed multiple topics: one on non-pharmacological treatment (Korea), two on treatment (APA, RANZCP) $[23,24]$ and five on diagnosis and treatment (CANMAT, NICE, GuiaSalud, VADoD, BAP). Of note, three CPGs issued consensus statements (either GCPs or consensusbased recommendations).

In general, 6/11 CPGs provided recommendations on screening (CANMAT, NICE, GuiaSalud, USTF, VADoD, BAP), 5/11 on diagnosis (CANMAT, NICE, GuiaSalud, VADoD, BAP), 8/11 on pharmacological treatment (of which, six established the first line of treatment [CANMAT, GuiaSalud, APA, RANZCP, VADoD, BAP], and five established first and the second line of treatment [CANMAT, GuiaSalud, APA, RANZCP, BAP]), 9/11 on non-pharmacological treatments (all of them discussed psychological treatment [CANMAT, NICE, GuiaSalud, ACP, APA, RANZCP, VADoD, Korea, BAP], seven provided recommendations on the use of electro-stimulation therapy [CANMAT, NICE, GuiaSalud, APA, RANZCP,
VADoD, BAP], six on St. John's wort [CANMAT, NICE, GuiaSalud, APA, VADoD, BAP], and two on acupuncture [CANMAT, Acupuncture CPG]) (Table 2).

To assess the quality of guidelines, we used the AGREE II instrument. The overall assessment score ranged from 53 to $87 \%$ (mean: $70.8 \%$ ), and $4 / 11$ guidelines had an overall assessment score $\geq 70 \%$ (NICE, ACP, USTF, VADoD). Regarding the third domain, scores ranged from 45 to $88 \%$ (mean: $62.9 \%$ ), and $3 / 11$ guidelines had a score $\geq 70 \%$ (NICE, ACP, VADoD) (Table 3).

Regarding the quality of the systematic review, 11/11 of the included CPGs stated what databases they used, 5/11 CPGs published their search strategy (CANMAT, NICE, ACP, USTF, VADoD), 4/11 CPGs presented the included studies (NICE, GuiaSalud, ACP, USTF), and 6/ 11 CPGs mentioned the risk of bias assessment as part of their methodology (NICE, GuiaSalud, ACP, USTF, VADoD, BAP) (Table 3).

\section{Discussion \\ Main findings}

This study explores the characteristics, scope, and quality of CPGs for depression in adults that based their recommendations on systematic reviews and were published between January 2014 and May 2018. We included eleven CPGs from seven countries on four continents, from which two reported the patient involvement in the design or validation of the CPGs, six provided recommendations on screening, five on diagnosis, eight on pharmacological treatment, nine on psychological treatment, nine on other non-pharmacological treatments. Regarding the quality assessment, $4 / 11$ CPGs reached a score $\geq 70 \%$ in the overall assessment of the AGREE-II instrument, and 3/11 CPGs reached a score $\geq 70 \%$ in the rigor of development domain. In addition, only 5/11 CPGs shared their search strategy, while only $4 / 11$ listed the selected studies they used to reach recommendations, and 7/11 CPGs did not clearly state which methodology they used to translate evidence into a recommendation.

\section{Patient involvement}

The involvement of patients or their representatives in the development of CPGs is considered important as it is supposed to complement scientific evidence to reach more acceptable and implementable recommendations [29]. Thus, many guidelines development groups recommend its inclusion in every step through the development of CPGs, including the definition of the scope and objectives, the definition of the review questions, the developing of recommendations (sharing their preferences regarding the assessed interventions), and the review of the final version of the CPG [30].

However, we found that 2/11 CPGs reported that patients had participated in the design or validation of 


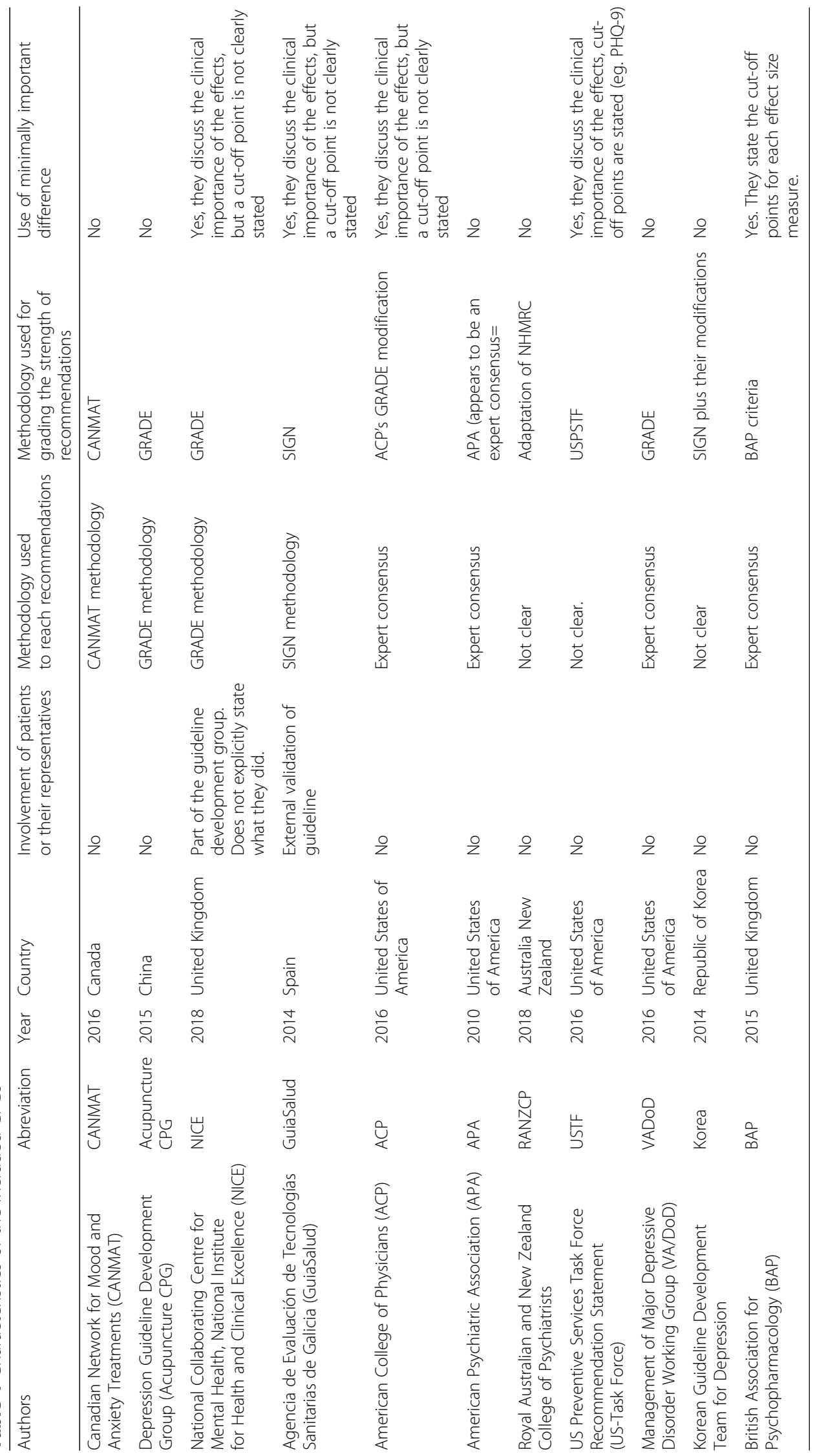




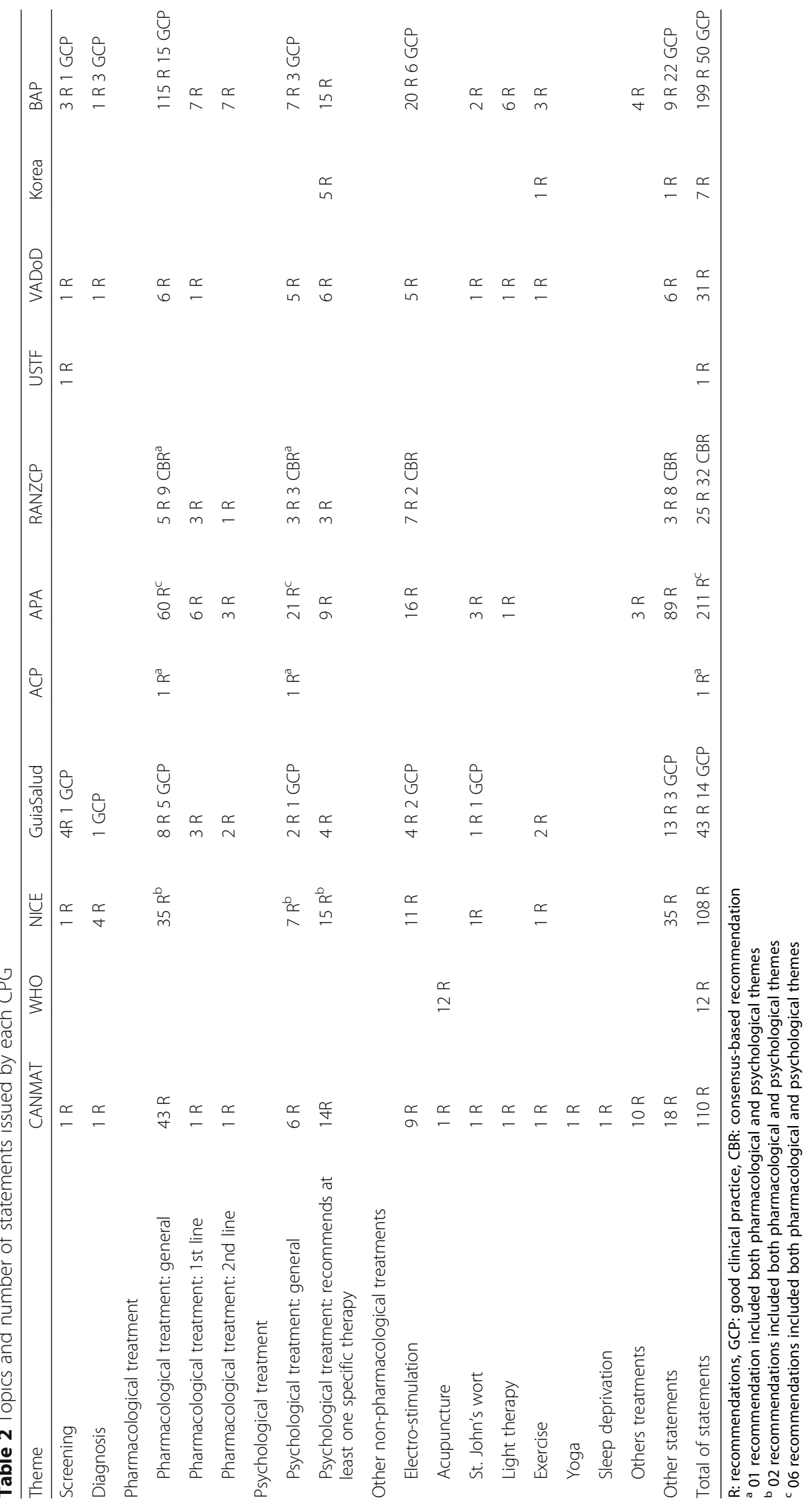




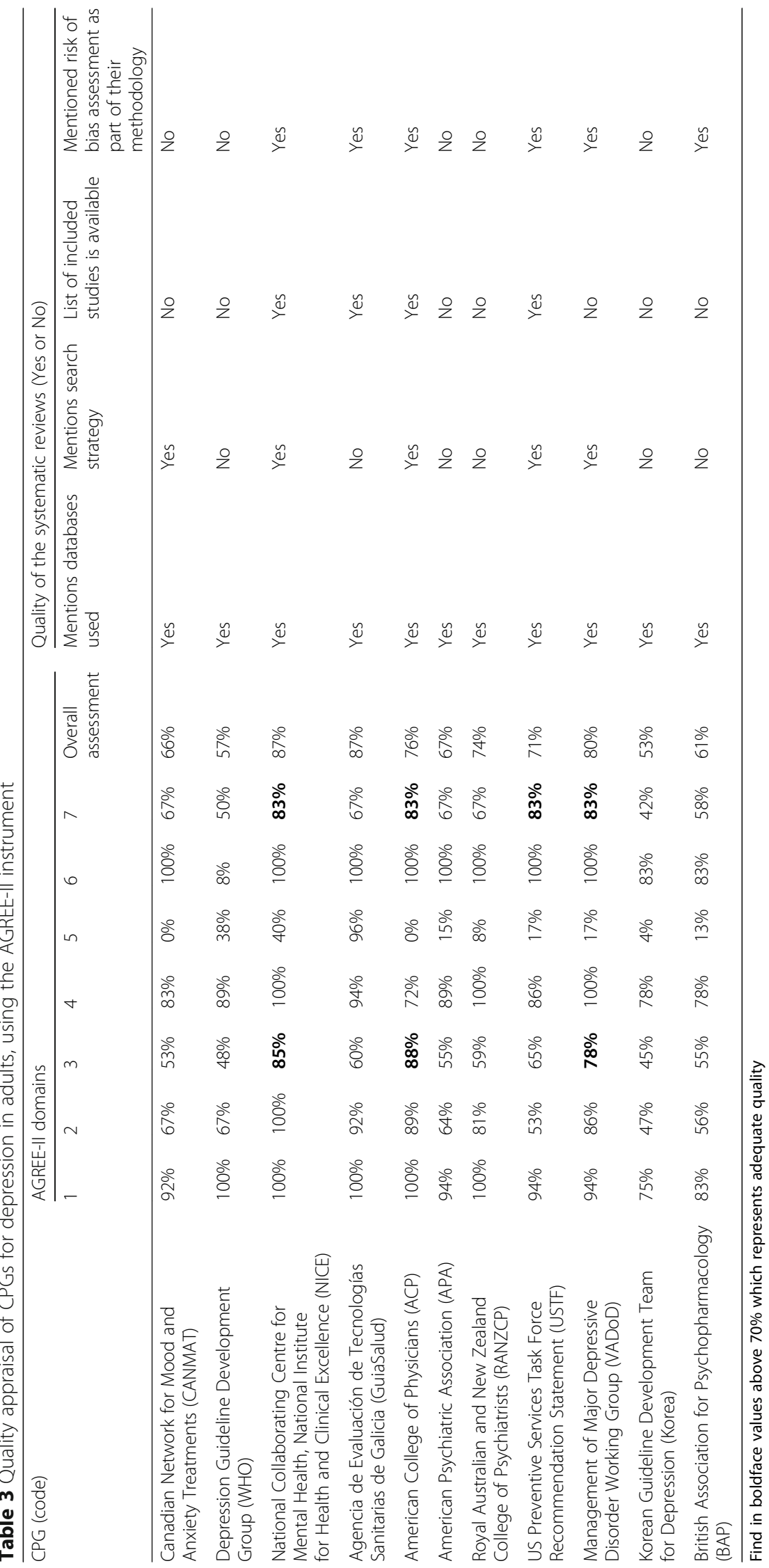


the CPGs. This low patient involvement is similar to that found in other studies. One study that evaluated 62 Dutch guidelines assessed patients' participation in the development process through three items (patients' participation, identification of the patient's input in the CPG, and the emphasis of patients' participation in the individual patient level), and found that only $1 / 62 \mathrm{CPGs}$ fulfilled satisfactorily these items [31]. The CPG that fulfilled these criteria was the Dutch guideline for depression [32]. Moreover, a study evaluated the patient involvement in guidelines in 101 organizations that publish CPGs in G-I-N North America and National Guideline Clearinghouse and found that only $8 \%$ of them require the patient or public involvement on guideline development groups, while 15\% sometimes require it or describe it as optional [33].

\section{Quality of the CPGs}

When focusing on the third domain of the AGREE II Instrument (rigor of development), few CPGs $(3 / 11=27 \%)$ reached a score $\geq 70 \%$. This is similar to a systematic review of CPGs for depression in children and youth that found that only $4 / 17=17.6 \%$ achieved a score $\geq 70 \%$ in this domain [8]. Other studies have reached different results regarding the percentage of CPGs that achieved a score $\geq 70 \%$ in the third domain on the AGREE-II instrument. i.e.: $1 / 11=9.1 \%$ for Heparin-induced thrombocytopenia CPGs [34], 15/115 $=13.0 \%$ for kidney transplantation CPGs [35], $5 / 30=16.6 \%$ for fertility preservation in young women undergoing gonadotoxic treatment CPGs [36], $6 / 17=35.3 \%$ for pediatric traumatic brain injury CPGs [37], and 5/12 $=41.7 \%$ for treatments for oral cancer CPGs [38].

Our results indicate that few of the CPGs achieve an adequate methodological quality, which could lead to recommendations that are not based on the best available evidence. This situation could be due to the fact that developing a high-quality CPG demands many financial resources, time, highly specialized personnel, and health system support [39-41]. In addition, some CPGs may fulfill an adequate rigor of development but attained a low score in the AGREE-II instrument because the development process was not adequately reported [42]. To avoid this, the guideline development groups could apply AGREE-II or another instrument to verify the adequate reporting of their CPGs.

To state a recommendation, two basic steps are needed: the selection of evidence and the methodology used to translate evidence into a recommendation [5]. We evaluated some characteristics in order to understand how these steps were performed.

Regarding the selection of evidence, only 5/11 CPGs shared their search strategy, while only $4 / 11$ listed the selected studies they used to reach recommendations.
Not sharing these information prevents the readers from adequately evaluating if there was any bias in the selection of evidence used to guide the recommendations, and prevents the replication and corroboration of the searches performed.

Regarding the methodology used to translate evidence into a recommendation, 7/11 CPGs did not clearly state the methodology used. A clearly defined methodology is necessary to understand what criteria were used and how the developing group judged each criterion to reach a recommendation. This allows users to understand how subjectivity and possible competing interest of the guideline developing group may have influenced on its recommendations, and help decide if recommendations can or should be implemented in their own settings [43]. Inconsistent recommendations are not rare, as shown by a systematic review that assessed the recommendations stated in CPGs for depression treatment, which found inconsistencies in the recommendations for the second and third line of pharmacological treatment [7]. For CPGs with inadequate methodology, it is necessary to evaluate the suitability of its use, and be careful when considering the implementation of its recommendations.

\section{Limitations and strengths}

Our study is not free from limitations. We only collected guidelines published in English or Spanish, so our findings could not be representative of CPGs published in other languages. The CGPs quality was assessed using the AGREE-II instrument, based on the reporting of the CPGs, so guidelines with inadequate reporting could be classified as deficient, despite their actual quality. Lastly, there are not validated cut-off points for the AGREE-II instrument so the discrimination between CPGs with adequate and inadequate quality could be inaccurate.

However, to our knowledge, this is the first study that has evaluated the characteristics and quality of CPGs for depression in adults. This evaluation has some important strengths: we used a systematic search strategy involving eighteen databases to find available CPGs for depression in adults, we used the AGREE-II instrument that provides a standard methodology to critically appraise the quality of CPGs, and we performed independent appraisals by two researchers.

\section{Conclusions}

We found eleven CPGs for depression in adults that used systematic reviews to guide their recommendations. Only two CGPs reported patient involvement. Regarding the quality of these CPGs, only 4/11 CPGs reached a score $\geq 70 \%$ in the overall assessment of the AGREE-II instrument, and 3/11 CPGs reached a score $\geq 70 \%$ in the rigor of development domain. In addition, only 5/11 
CPGs shared their search strategy, while only $4 / 11$ listed the selected studies they used to reach recommendations, and 7/11 CPGs did not clearly state which methodology they used to translate evidence into a recommendation. These findings should be taken into account by stakeholders, CPGs developers, and CPGs users; when choosing CPGs, and interpreting and putting into practice their issued recommendations from CPGs for depression in adults.

\section{Additional files}

Additional file 1: Search strategies and results for CPGs for depression. We present the list of databases or CPG repositories, the search strategy and the results from the searches. (DOCX $14 \mathrm{~kb}$ )

Additional file 2: Flowchart of selection of CPGs. We present the flowchart of how we selected the CPGs that were included in our study. (DOCX $21 \mathrm{~kb})$

\section{Abbreviations}

AGREE-II: Appraisal of Guidelines Research and Evaluation II; CANMAT: Canadian Network for Mood and Anxiety Treatments; CPGs: Clinical practice guidelines; GCP: Good clinical practice; GRADE: Grades of Recommendation, Assessment, Development, and Evaluation; MID: Minimally important difference; SIGN: Scottish Intercollegiate Guidelines Network

\section{Acknowledgments}

Not applicable.

\section{Funding}

This study was self-funded.

\section{Availability of data and materials}

All data generated or analyzed during this study are included in this published article [and its supplementary information files].

\section{Authors' contributions}

All authors designed the study. JHZT, DVZ, and SGL collected the data. All authors performed the statistical analyses, participated in in the interpretation of the results, participated in the writing of the manuscript, and approved its final version.

\section{Ethics approval and consent to participate}

Not applicable.

\section{Consent for publication}

Not applicable.

\section{Competing interests}

The authors declare that they have no competing interests.

\section{Publisher's Note}

Springer Nature remains neutral with regard to jurisdictional claims in published maps and institutional affiliations.

\section{Author details}

${ }^{1}$ Universidad Peruana Cayetano Heredia, CRONICAS Centre of Excellence for Chronic Diseases, Lima, Peru. ${ }^{2}$ Independent researcher, Lima, Peru. ${ }^{3}$ Instituto Peruano de Orientación Psicológica, Lima, Peru. ${ }^{4}$ Universidad San Ignacio de Loyola, Unidad de Investigación para la Generación y Síntesis de Evidencias en Salud, Av. La Fontana 550, La Molina, Lima, Peru.
Received: 24 September 2018 Accepted: 12 February 2019

Published online: 20 February 2019

\section{References}

1. World Health Organization. Depression and Other Common Mental Disorders: Global Health Estimates. Geneva: World Health Organization; 2017

2. Institute for Health Metrics and Evaluation. Global Burden of Disease Compare Viz Hub: University of Washington; 2018 [Available from: https://vizhub.healthdata.org/gbd-compare/.

3. National Center for complementary and Integrative Heatlh. Clinical Practice Guidelines: U.S. Department of Health \& Human Services; 2017 [Available from: https://nccih.nih.gov/health/providers/clinicalpractice.htm.

4. Field B, Booth A, llott I, Gerrish K. Using the knowledge to action framework in practice: a citation analysis and systematic review. Implement Sci. 2014. 9(1):172.

5. Guyatt G, Oxman AD, Akl EA, Kunz R, Vist G, Brozek J, et al. GRADE guidelines: 1. Introduction-GRADE evidence profiles and summary of findings tables. J Clin Epidemiol. 2011;64(4):383-94.

6. Rosenfeld RM, Shiffman RN, Robertson P. Clinical practice guideline development manual: a quality-driven approach for translating evidence into action. Otolaryngol Head Neck Surg. 2013;148(1_suppl):S1-S55.

7. Bayes A, Parker G. Comparison of guidelines for the treatment of unipolar depression: a focus on pharmacotherapy and neurostimulation. Acta Psychiatr Scand. 2018;137(6):459-71.

8. Bennett K, Courtney D, Duda S, Henderson J, Szatmari P. An appraisal of the trustworthiness of practice guidelines for depression and anxiety in children and youth. Depress Anxiety. 2018;35(6):530-40.

9. Tricco AC, Lillie E, Zarin W, O'Brien KK, Colquhoun H, Levac D, et al. PRISMA extension for scoping reviews (PRISMA-SCR): checklist and explanation. Ann Intern Med. 2018;169(7):467-73.

10. Colquhoun HL, Levac D, O'Brien KK, Straus S, Tricco AC, Perrier L, et al. Scoping reviews: time for clarity in definition, methods, and reporting. J Clin Epidemiol. 2014;67(12):1291-4.

11. Munn Z, Peters MD, Stern C, Tufanaru C, McArthur A, Aromataris E. Systematic review or scoping review? Guidance for authors when choosing between a systematic or scoping review approach. BMC Med Res Methodol 2018;18(1):143.

12. IOM (Institute of Medicine). Clinical Practice Guidelines We Can Trust. Washington, DC: The National Academies Press; 2011.

13. Johnston A, Kelly SE, Hsieh S-C, Skidmore B, Wells GA. Systematic reviews of clinical practice guidelines: a methodological guide. J Clin Epidemiol. 2018; 108:64-76.

14. Johnston BC, Ebrahim S, Carrasco-Labra A, Furukawa TA, Patrick DL, Crawford MW, et al. Minimally important difference estimates and methods: a protocol. BMJ Open. 2015;5(10):e007953.

15. Brouwers MC, Kho ME, Browman GP, Burgers JS, Cluzeau F, Feder G, et al. AGREE II: advancing guideline development, reporting and evaluation in health care. Can Med Assoc J. 2010;182(18):E839-E42.

16. Washington KFHPo. Adult and Adolescent Depression Screening, Diagnosis, and Treatment Guideline: Kaiser Permanente; 2017 [Available from: https:// wa.kaiserpermanente.org/static/pdf/public/guidelines/depression.pdf.

17. Trangle M, Gursky J, Haight R, Hadwig J, Hinnekamp T, Kessler D, et al. Adult depression in primary care. Bloomington, MN: Institute for Clinical Systems Improvement; 2016.

18. Lam RW, Kennedy SH, Parikh SV, MacQueen GM, Milev RV, Ravindran AV. Canadian network for mood and anxiety treatments (CANMAT) 2016 clinical guidelines for the management of adults with major depressive disorder: introduction and methods. Can J Psychiatry. 2016;61(9):506-9.

19. Zhao H, Sun YX, Luo HC, Guo X, Zi MJ, Liu J, et al. Clinical practice guidelines for using acupuncture to treat depression. Chin J Integr Med. 2015.

20. National Institute for Clinical Excellence. The treatment and management of depression in adults (updated edition) National Clinical Practice Guideline 90. The British Psychological Society and The Royal College of Psychiatrists. 2010.

21. Grupo de trabajo de la Guía de Práctica Clínica sobre el Manejo de la Depresión en el Adulto. Guía de Práctica Clínica sobre el Manejo de la Depresión en el Adulto. Ministerio de Sanidad, Servicios Sociales e Igualdad. Agencia de Evaluación de Tecnologías Sanitarias de Galicia (avalia-t); 2014. Guías de Práctica Clínica en el SNS: Avalia-t 2013/06. [Available from: http:// www.guiasalud.es/egpc/depresion/completa/general/copyright.html. 
22. Qaseem A, Barry MJ, Kansagara D. Nonpharmacologic versus pharmacologic treatment of adult patients with major depressive disorder: a clinical practice guideline from the American College of Physicians. Ann Intern Med. 2016;164(5):350-9.

23. Gelenberg AJ, Freeman MP, Markowitz JC, Rosenbaum JF, Thase ME, Trivedi $\mathrm{MH}$, et al. Practice guideline for the treatment of patients with major depressive disorder third edition. Am J Psychiatry. 2010;167(10):1.

24. Malhi GS, Outhred T, Hamilton A, Boyce PM, Bryant R, Fitzgerald PB, et al. Royal Australian and New Zealand College of Psychiatrists clinical practice guidelines for mood disorders: major depression summary. Med J Aust. 2018;208(4):175-80.

25. O'Connor E, Rossom RC, Henninger M, Groom HC, Burda BU, Henderson JT, et al. U.S. preventive services task force evidence syntheses, formerly systematic evidence reviews. Screening for depression in adults: an updated systematic evidence review for the US preventive services task force. Rockville (MD): Agency for Healthcare Research and Quality (US); 2016.

26. Management of Major Depressive Disorder Working Group. VAVDoD clinical practice guideline for the management of major depressive disorder: Washington (DC): Department of Veterans Affairs, Department of Defense; 2016 [Available from: https://www.healthquality.va.gov/guidelines/MH/mdd/.

27. Park S-C, Oh HS, Oh D-H, Jung SA, Na K-S, Lee H-Y, et al. Evidence-based, non-pharmacological treatment guideline for depression in Korea. J Korean Med Sci. 2014;29(1):12-22.

28. Cleare A, Pariante CM, Young AH, Anderson IM, Christmas D, Cowen PJ, et al. Evidence-based guidelines for treating depressive disorders with antidepressants: a revision of the 2008 British Association for Psychopharmacology guidelines. J Psychopharmacol. 2015;29(5):459-525.

29. van der Ham AJ, van Erp N, Broerse JE. Monitoring and evaluation of patient involvement in clinical practice guideline development: lessons from the multidisciplinary guideline for employment and severe mental illness, the Netherlands. Health Expect. 2016;19(2):471-82.

30. Selva A, Sanabria AJ, Pequeño S, Zhang Y, Sola I, Pardo-Hernandez H, et al. Incorporating patients' views in guideline development: a systematic review of guidance documents. J Clin Epidemiol. 2017;88:102-12.

31. van de Bovenkamp HM, Zuiderent-Jerak T. An empirical study of patient participation in guideline development: exploring the potential for articulating patient knowledge in evidence-based epistemic settings. Health Expect. 2015;18(5):942-55.

32. Spijker J, Bockting C, Meeuwissen J, Van Vliet I, Emmelkamp P, Hermens M, et al. Multidisciplinaire richtlijn Depressie (Derde revisie): Richtlijn voor de diagnostiek, behandeling en begeleiding van volwassen patiënten met een depressieve stoornis. In: Multidisciplinary guidelines for depression (third revision): Guideline for the diagnosis, treatment and guidance of adult patients with a depressive disorder. Utrecht: Trimbos Instituut; 2013.

33. Armstrong MJ, Bloom JA. Patient involvement in quidelines is poor five years after institute of medicine standards: review of guideline methodologies. Res Involvement Engagement. 2017;3(1):19.

34. Wang Y, Ye Z-K, Li J-F, Cui X-L, Liu L-H. Heparin-induced thrombocytopenia: a critical appraisal of clinical practice guidelines with the AGREE II instrument. Thromb Res. 2018;166:10-8.

35. O'Donoghue KJM, Reed RD, Knight SR, O'Callaghan JM, Ayaz-Shah AA, Hassan S, et al. Critical appraisal of international clinical practice guidelines in kidney transplantation using the appraisal of guidelines for research and education II tool: a systematic review. Transplantation. 2018;102(9):1419-39.

36. Baysal Ö, Hamilton JA, Hamilton CJ, Braat DD, Beerendonk CC, Nelen WL. Clinical practice guidelines for fertility preservation in young women undergoing gonadotoxic treatment: an overview and critical appraisal of methodological quality and content. Reprod BioMed Online. 2018;37(1):60-70.

37. Appenteng R, Nelp T, Abdelgadir J, Weledji N, Haglund M, Smith E, et al. A systematic review and quality analysis of pediatric traumatic brain injury clinical practice guidelines. PLoS One. 2018;13(8):e0201550.

38. Anaya MVM, Franco JV, Merchán-Galvis ÁM, Gallardo CR, Cosp XB. Quality assessment of clinical practice guidelines on treatments for oral cancer. Cancer Treat Rev. 2018;65:47-53.

39. Classen DC, Mermel LA. Specialty society clinical practice guidelines: time for evolution or revolution? Jama. 2015;314(9):871-2.

40. Pronovost PJ. Enhancing physicians' use of clinical guidelines. Jama. 2013; 310(23):2501-2.

41. Ransohoff DF, Pignone M, Sox HC. How to decide whether a clinical practice guideline is trustworthy. JAMA. 2013;309(2):139-40.
42. Yao L, Chen Y, Wang X, Shi X, Wang Y, Guo T, et al. Appraising the quality of clinical practice guidelines in traditional Chinese medicine using AGREE ॥ instrument: a systematic review. Int J Clin Pract. 2017;71(5):e12931.

43. Schunemann HJ, Mustafa R, Brozek J, Santesso N, Alonso-Coello P, Guyatt G, et al. GRADE guidelines: 16. GRADE evidence to decision frameworks for tests in clinical practice and public health. J Clin Epidemiol. 2016;76:89-98.
Ready to submit your research? Choose BMC and benefit from:

- fast, convenient online submission

- thorough peer review by experienced researchers in your field

- rapid publication on acceptance

- support for research data, including large and complex data types

- gold Open Access which fosters wider collaboration and increased citations

- maximum visibility for your research: over $100 \mathrm{M}$ website views per year

At BMC, research is always in progress.

Learn more biomedcentral.com/submissions 